R. J. Cohen and W. T. Sullivan, III, eds.

\title{
Bridges and Outdoor Lighting
}

\author{
Arthur Upgren \\ Wesleyan and Yale Universities
}

\begin{abstract}
Northeast Utilities, the electric power distributor for Connecticut, has devised a plan to light the Arrigoni Bridge across the Connecticut River at Middletown. This paper descibes the plan and its impact on the surrounding region. The floodlights will affect migratory birds, and teaching and research at the nearby Van Vleck Observatory on Wesleyan Campus. Examples of bridges at other sites are also discussed, including the suspension spans of New York and San Francisco, that bear only tracer lights, or no lights at all.
\end{abstract}

\section{Introduction}

Northeast Utilities, the electric power distributor for Connecticut, has devised a plan to illuminate the Arrigoni Bridge across the Connecticut River at Middletown, connecting that city with Portland just across the Connecticut River. The bridge, erected in 1938, features two steel arch spans, each 600 feet in length. It is shown in Figure 1.

The lighting plan calls for inductive discharge lamps, 172 of which are to be necklace or tracer lights of 55 watts, 3500 lumens each, that would outline the steel arches that form the superstructure of the bridge. In addition, 160 floodlights of 85 watts and 6000 lumens each, would be aimed upward, with an estimated $5 \%$ of the light falling on the arches and $95 \%$ or 912,000 lumens glaring directly up into the sky. An additional 28 lamps would illuminate the piers of the bridge below the roadway. These data are included in a brief summary of the plan, prepared in collaboration with the Lighting Research Center located at Troy, New York. The present paper describes the plan and its impact on the surrounding region and includes examples of bridges at a number of sites elsewhere (Figures 2 to 6 ).

\section{Bridge Lighting}

With few exceptions, prominent bridges such as the suspension spans of New York and San Francisco, bear only tracer lights, or no lights at all beyond a number that illuminate the roadway. The Hernando DeSoto Memorial Bridge, spanning the Mississippi River at Memphis, is a double-steel-arch twin of the Middletown bridge. It served as the prototype for the plan, but carries only tracer lights, some 200 bright HPS lamps of 6000 lumens each, as shown in Figure 2. 


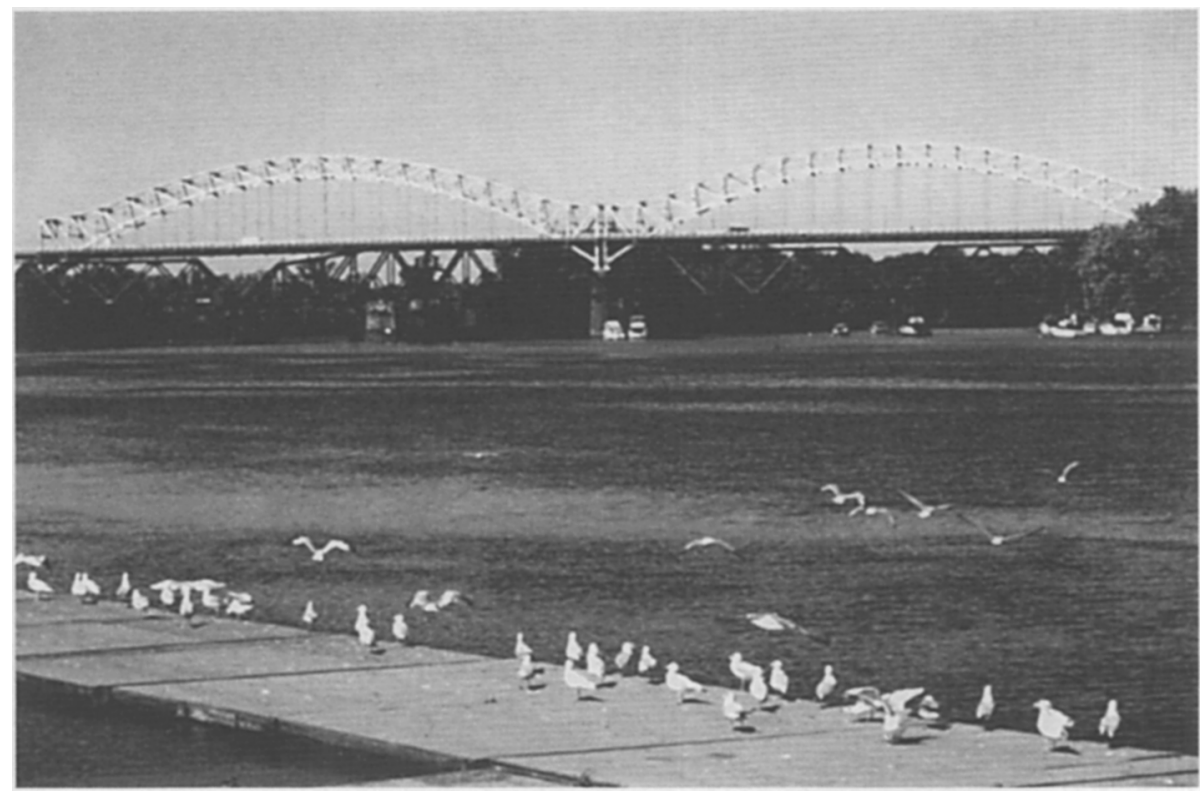

Figure 1. The Arrigoni Bridge at Middletown, CT, showing the two 600 -foot $(183-\mathrm{m})$ steel arches. The lighting plans call for 172 tracer lights and 160 floodlights pointed upward, with an estimated $5 \%$ of the light illuminating the arches and $95 \%$ shining directly into the sky.

Of the bridges studied, only two incorporate upward-shining floods in their lighting design. The new Akashi Kaikyo Suspension Bridge in Japan, the world's largest, restricts upward-shining light to its two towers (Figure 5). The same appears to be the case for the George Washington Bridge in New York.

Northeast Utilities, through its associate, Connecticut Power \& Light, has provided details, although the citizens of Middletown and Portland are still mostly unaware of the plan and its estimated cost, which is projected at $\$ 764,000$ for the installation of the lights and an annual amount of $\$ 20,000$ for lighting energy consumption and maintenance. A model of the bridge is on public display, but provides no lighting details. The floodlights will affect migratory birds, and teaching and research at the nearby Van Vleck Observatory on the Wesleyan campus may be impaired. The extent of the damage to the environment is still uncertain should this plan be approved and financed.

From the bridges depicted here and others, most, even famous ones, appear to have been limited to tracer lights of low light pollution levels. I know of only one other case of an intent to floodlight an entire span. This is the Humber Bridge, a suspension bridge across the Humber River at Hull, the longest bridge in England. I have been informed recently, that the plan to install 72 floodlights has been dropped. But it is vital for us to be aware of and forestall any emerging trend towards illuminating the superstructures of bridges. 


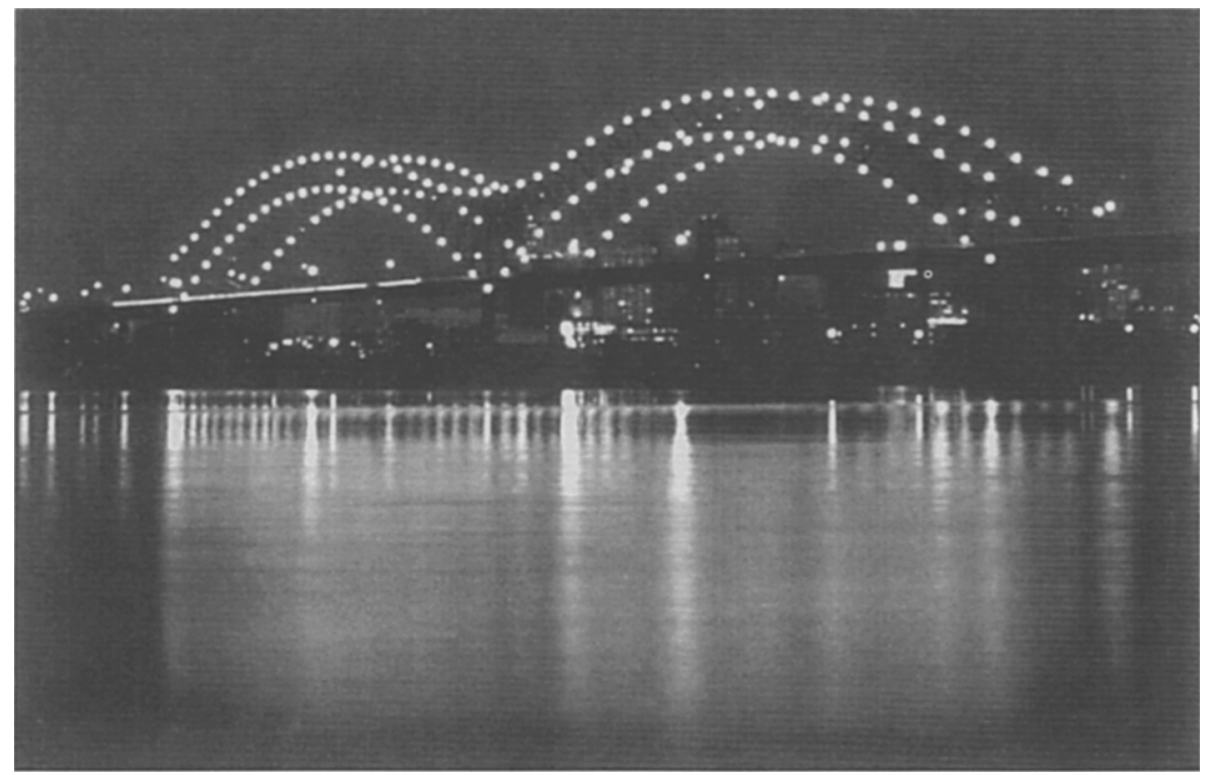

Figure 2. Hernando DeSoto Memorial Bridge at Memphis is a near twin of the Arrigoni Bridge and served as a model for the lighting plan. The 200 tracer lights are HPS 6300 lumens each. There are no floodlights.

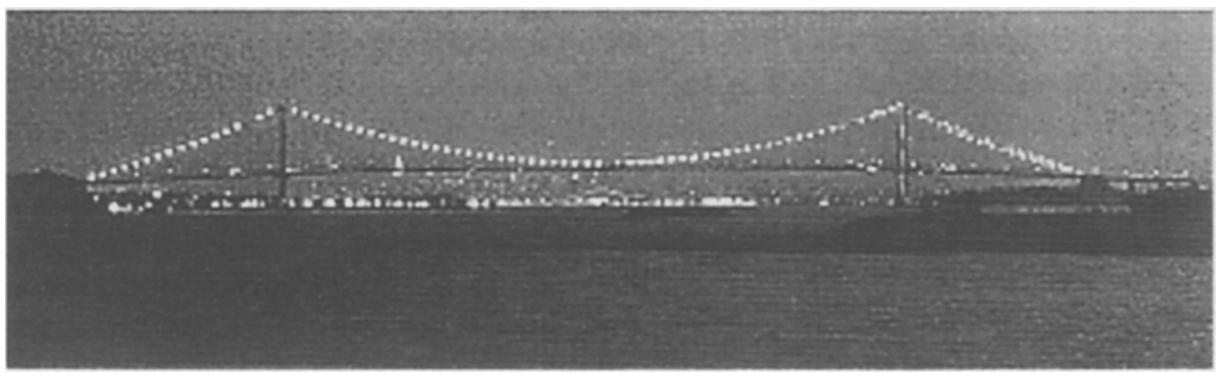

Figure 3. The Bronx-Whitestone Bridge, linking the boroughs of Bronx and Queens in New York, shows the necklace or tracer lights that are in common use throughout the city's many suspension bridges. 


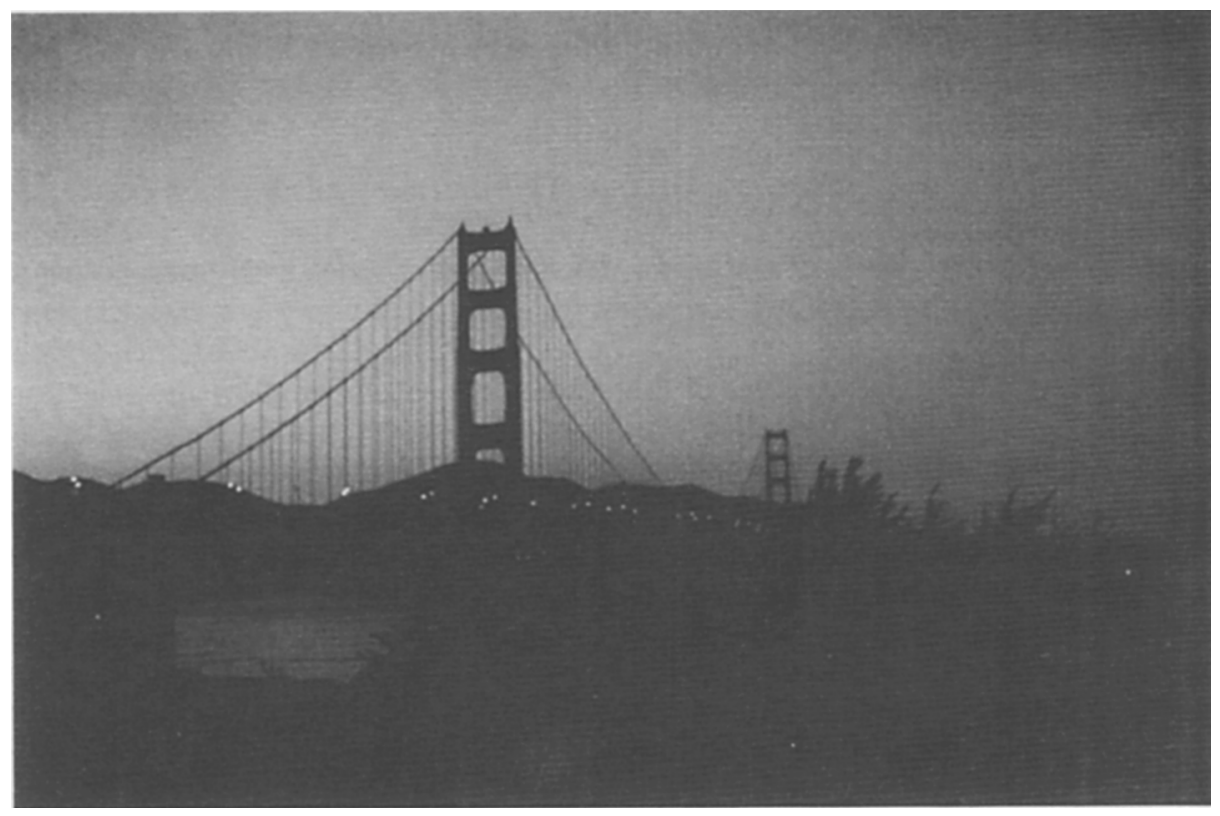

Figure 4. The Golden Gate Bridge in San Francisco. This span incorporates only roadway lighting.

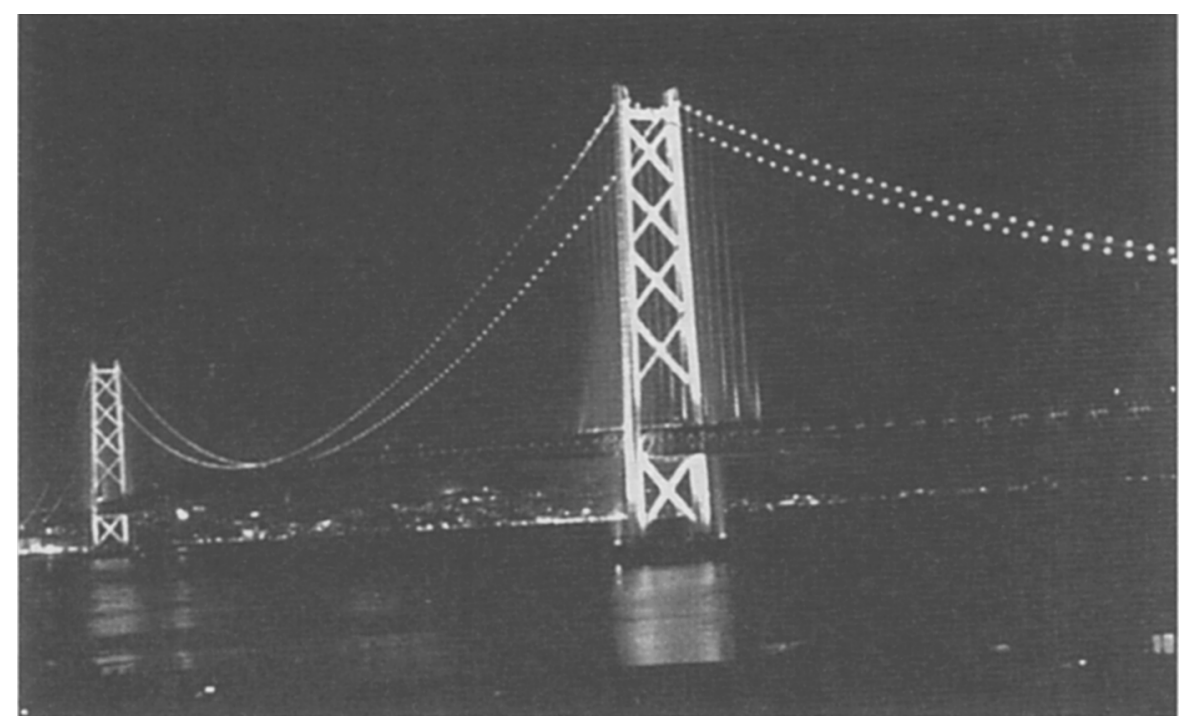

Figure 5. The new Akashi Kaikyo Bridge near Kobe, Japan. Floodlights illuminate only the two towers, each 300 meters (984 feet) high, just equal in height to the Eiffel Tower. 